\title{
Sex dependent differences in physiological ageing in the immune system of lower airways in healthy non-smoking volunteers: study of lymphocyte subsets in bronchoalveolar lavage fluid and blood
}

\author{
E Mund, B Christensson, K Larsson, R Grönneberg
}

\begin{abstract}
Background-Age related changes in the immune system have been studied frequently but a possible relation to sex has not, to our knowledge, previously been examined. The effect of age and sex on the composition of lymphocyte subsets in bronchoalveolar lavage (BAL) fluid and peripheral blood was therefore examined. Methods-Bronchoscopy with lavage was performed in 32 healthy non-atopic, nonsmoking volunteers (16 women aged 26-63 years (mean 44) and 16 men aged 23-63 years (mean 39)). Cytospin preparations for differential counts of BAL fluid cells and surface antigen expression of lymphocytes from BAL fluid and blood were analysed by flow cytometry.
\end{abstract}

Results-Most parameters in the BAL fluid changed with age in women. The percentage of CD4+ lymphocytes increased with age from a mean of 48 (SD10)\% in women aged $\leqslant 40$ years to 69 (11) \% in women aged $>43$ years $(p=0.001)$. The percentage of $\mathrm{CD} 8+$ lymphocytes tended to decrease with age and the CD4/ CD8 ratio was $5.8(1.2)$ in women aged $>43$ years compared with $2.1(0.7)$ in those aged $\leqslant 40$ years $(p<0.0001)$. Women aged $>43$ years differed from men aged $>43$ years as well as from younger subjects of both sexes with respect to CD4+ cells and CD4/CD8 ratio, and from younger women with respect to $\mathrm{CD8}+$ cells. There was no age related change in the $\mathrm{CD} 4 / \mathrm{CD} 8$ ratio in blood. No sex related differences were seen in the blood or BAL fluid of adults below the age of 40 years.

Conclusions-The composition of 1ymphocytes with different phenotypes in the lower respiratory tract changes with age in women but not in men. This may have implications for some clinical conditions such as chronic dry cough which are observed predominantly in women.

(Thorax 2001;56:450-455)

Keywords: age; bronchoalveolar lavage fluid; sex; $\mathrm{T}$ cells

It has recently become apparent that the immune system in humans undergoes a profound and complex change during their life span. The immunological, cellular, and humoral functions decline successively with age, which may be related to infections, malignancies, and autoimmune diseases in the elderly. ${ }^{1}$ Experimental data from various species and cell lines, as well as clinical observations, indicate that pronounced changes take place in $\mathrm{T}$ lymphocytes with ageing. ${ }^{1-4}$ The number of naive $T$ cells declines as a result of thymic involution which begins in early adulthood, sometimes even before puberty. ${ }^{5}$ Another fundamental change is the ageing of mature $T$ cells which results in a decline in the functional capacity of individual T cells. ${ }^{67}$ The most consistent change with ageing-namely, the progressive shift from a predominance of naive cells to memory cells within the CD4+ subpopulation - is, however, believed to reflect a more cumulative antigenic exposure during the life span rather than being a consequence of ageing.

Human studies in peripheral blood taken from subjects ranging in age from newborn infants to 102 years showed that the number of CD4+ T helper cells, particularly the memory helper cells and the CD4/CD8 ratio, increases with age. ${ }^{9-12}$ Corresponding systematic studies in the airways are sparse but a parallel age related increase in the $\mathrm{CD} 4 / \mathrm{CD} 8$ ratio has been described in the blood and bronchoalveolar lavage (BAL) fluid. ${ }^{13}$ While in children the CD4/CD8 ratio is higher in blood than in BAL fluid, ${ }^{14}$ in adults the opposite is true. ${ }^{1516}$ Thompson et al and Meyer et al examined groups of young, middle aged, and older subjects and found that the CD4/CD 8 ratio was significantly higher in the elderly subjects (65-80 years) than in the younger groups (19-36 years), and that the difference was more pronounced in BAL fluid than in peripheral blood. ${ }^{17-19}$

However, only a few studies of lymphocyte phenotypes in BAL fluid and blood have considered the effects of both sex and age. In a multicentre study of healthy subjects the impact of sex was analysed and an increase in the total number of $\mathrm{T}$ cells, $\mathrm{T}$ suppressor cells, and $\mathrm{B}$ cells and a lower $\mathrm{CD} 4+/ \mathrm{CD} 8+$ ratio were found in BAL fluid from men compared with women. Such sex related differences were not found in peripheral blood. ${ }^{20}$ A study on age and sex related changes in blood lymphocyte subpopulations in healthy Asian subjects from birth up to 40 years found only limited sex dependent differences - generally higher natural killer (NK) subsets in absolute numbers in males and higher numbers of CD4 subsets in females throughout most age groups, but 
statistical significance was found only in the cord blood of newborn infants. ${ }^{21}$ In a Japanese study it was shown that $T$ helper cells increased and cytotoxic $\mathrm{T}$ cells decreased with age in blood from healthy females. ${ }^{10}$

The aim of the present study was to examine the effect of age and sex on the immune defence system of the lower respiratory tract and peripheral blood with regard to lymphocyte subsets in healthy non-smoking volunteers.

\section{Methods}

SUBJECTS

Thirty two healthy non-atopic volunteers were included in the study (16 women of mean age 44 years (range 26-63) and 16 men of mean age 39 years (range 23-63)). The participants were life long non-smokers except for one women who stopped smoking 10 years before the study after having smoked for 10 years. The subjects were recruited from medical students, hospital staff, and their relatives. The participants had no history of atopy or lung diseases. Except for one man who used enalapril for treatment of hypertension, none of the participants took medicine on a regular basis. Most of the women (13/16) were not on hormone replacement therapy. Three women regularly used sex hormones (two women aged 39 and 53 years used vaginally applied oestrogen and one 58 year old woman had oestrogen replacement by the aid of a patch). All participants in the study were healthy with a normal chest radiograph, normal peak expiratory flow rate (PEFR), and normal routine blood tests. The results were analysed separately for women and men. Verbal and written information was given to all participants and the study was approved by the ethics committee of the Huddinge University Hospital at the Karolinska Institutet.

\section{STUDY DESIGN}

At the first visit a routine physical examination of heart and lungs, a chest radiograph, and PEFR were performed. If a positive history of allergy could not be excluded we obtained a negative skin prick test for routine airborne allergens. At the second visit bronchoscopic examination with bronchoalveolar lavage was performed and blood samples were taken.

BRONCHOALVEOLAR LAVAGE (BAL)

All bronchoscopic examinations were performed by the same investigator (EM). Subjects were premedicated subcutaneously with 4-8 mg oxycodon and $0.2-0.4 \mathrm{mg}$ scopolamine hydrobromide 30 minutes before the procedure. A fibreoptic bronchoscope (Olympus $1 \mathrm{~T} 20 \mathrm{D}$, Olympus Corporation, NY, USA) was inserted via the nasal route and wedged at the segmental or subsegmental level in the right middle lobe. Lidocaine (Xylocain, Astra, Sweden) was used for topical anaesthesia. Six aliquots of $25 \mathrm{ml} 0.9 \%$ saline $\left(37^{\circ} \mathrm{C}\right)$ were instilled and gently aspirated into a siliconised plastic bottle kept on ice. The first portion recovered was not used for analysis but fractions 2-6 were pooled for subsequent analyses.
DIFFERENTIAL COUNT OF CELLS IN BAL FLUID Total cell counts in BAL fluid were measured in a Bürker chamber after staining with Türk's solution, and the differential counts were performed using Giemsa stained cytospin preparations. The proportions of lymphocytes, macrophages, polymorphonuclear neutrophils, and eosinophils were calculated on counts of at least 500 cells. The percentages as well as the cell concentrations were determined. Twenty $\mathrm{ml}$ of pooled fractions 2-6 were filtered through a nylon mesh and centrifuged for 5 minutes at $400 \mathrm{~g}$. The cell viability was determined by Trypan blue exclusion.

IMMUNOSTAINING

The cells in the BAL fluid and blood were stained according to the same protocol.

The frequency of $\mathrm{B}$ (CD19+) and $\mathrm{T}$ $(\mathrm{CD} 3+)$ lymphocytes and the subsets of CD3+ cells, CD4+ ( $\mathrm{T}$ helper) cells, CD8+ ( $\mathrm{T}$ cytotoxic) cells, activated T cells (HLA-DR+, CD25+ and CD69+ cells), and CD56+CD16+ (NK cells) were determined by dual colour flow cytometry using a FACSCAN (Becton-Dickinson, Montainview, CA, USA). Combinations of fluorescein and phycoerythrin conjugated monoclonal antibodies (Becton-Dickinson) against the following antigens were used: $\mathrm{CD} 3, \mathrm{CD} 3 / \mathrm{CD} 4, \mathrm{CD} 3 / \mathrm{CD} 8$. Monoclonal antibodies specific for CD45/ CD14 and for irrelevant antigens served as positive and negative controls, respectively. Following 30 minutes of incubation with monoclonal antibodies, BAL fluid cells were washed in phosphate buffered saline (PBS) before analysis. Whole blood was stained with the same monoclonal antibodies, lysed with standard ammonium chloride solution, and washed in PBS before analysis.

\section{FLOW CYTOMETRY}

A minimum of 10000 cells were acquired and analysed using LYSIS II software (BectonDickinson). The lymphocyte gating for the determination of BAL fluid and blood lymphocyte subpopulations was made using forward and sidescatter parameters and was checked by backgating using a combination of anti-CD45/CD14 monoclonal antibodies and CD3+ stained cells.

STATISTICS

The effect of age and sex as continuous variables was detected by multiple regression with interaction (STATVIEW 1992-98, SAS Institute Inc, NC, USA). Correlations between increasing age and the percentage of CD3+ (T) cells and $\mathrm{T}$ cell subsets in the groups of women and men were detected by linear regression analysis; a $p$ value of $<0.05$ was considered significant. The Kruskal-Wallis and the MannWhitney U tests were used to detect differences between the young women and men $(<40$ years) and the middle aged women and men ( $\geqslant 44$ years). Comparisons of the groups were made by two tailed comparison of means. Due to multiple comparisons between groups composed of a limited number of subjects with the risk of mass significance, a $p$ value of $<0.01$ was 
considered significant. All results are presented as estimates of effect with $95 \%$ confidence intervals. Data are expressed as mean (SD) values or median values with $25-75$ th percentiles.

\section{Results}

BAL FLUID

The total cell number in the BAL fluid did not differ significantly between men and women (628 (400-982) $\times 10^{4}$ cells/ 1 in men, 521(171$732) \times 10^{4}$ cells $/ 1$ in women) .

Multiple linear regression with age and sex as continuous variables showed significant interaction for CD4 positive ( $\mathrm{T}$ helper) lymphocytes $(p=0.037)$ and for the CD4/CD8 ratio $(p=0.013)$. Age was found to have an effect on the relation between $\mathrm{T}$ helper and $\mathrm{T}$ cytotoxic cells in women but not in men (CD4/ CD8 ratio in women $\mathrm{p}=0.0003$, in men $\mathrm{p}=0.051)$. The effect of age was more prominent on CD4+ cells in women $(p=0.003)$ than in men $(p=0.048)$. Because of these differences between the sexes, correlations between age and $\mathrm{T}$ cell subsets and between age and the $\mathrm{CD} 4 / \mathrm{CD}$ ratio were analysed separately in women and men.

In women the percentage of CD4+ T helper cells increased significantly with age $(r=0.7$, $\mathrm{p}=0.003)$, the percentage of CD8 $+\mathrm{T}$ cytotoxic cells decreased with age $(r=-0.5)$ and, as a consequence, the CD4/CD8 ratio increased with age $(r=0.77, \mathrm{p}=0.0004$, fig 1$)$. A high CD4/CD8 ratio appeared first in a woman aged 44 years and was subsequently found to be high in all women above that age. The CD4/CD 8 ratio in women aged $44-62$ years was $4.4-8$ (mean 5.8) and in women aged 40 years or less it was 1.1-3 (mean 2.1). This difference in the ratio between $\mathrm{T}$ helper and $\mathrm{T}$ cytotoxic cells divided young and middle aged women into two separate groups (figs 1 and 2). The difference in the CD4/CD8 ratio in young and middle aged women was 3.68 (4.76-2.59, p<0.0001, figs 1 and 2). Differences in the proportions of CD4+ $\mathrm{T}$ helper cells and CD8+ T cytotoxic cells were
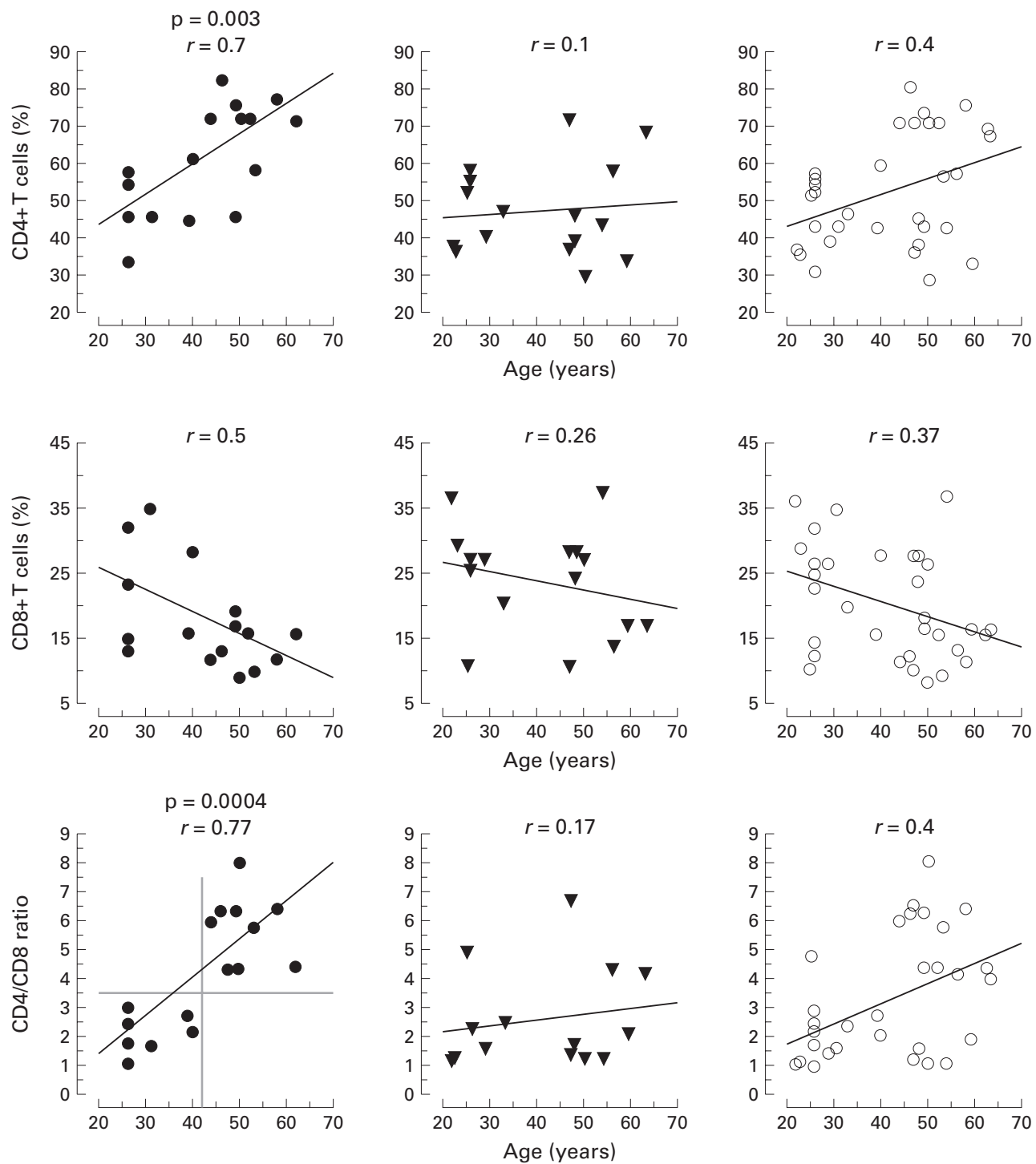

Women

Men

All subjects

Figure 1 Percentage of $C D 4+T$ cells, $C D 8+T$ cells, and $C D 4 / C D 8$ ratio in $B A L$ fluid in relation to age in women and men. Significant correlations are indicated ( $p$ values by Fisher's $r$ to $z$ test). 

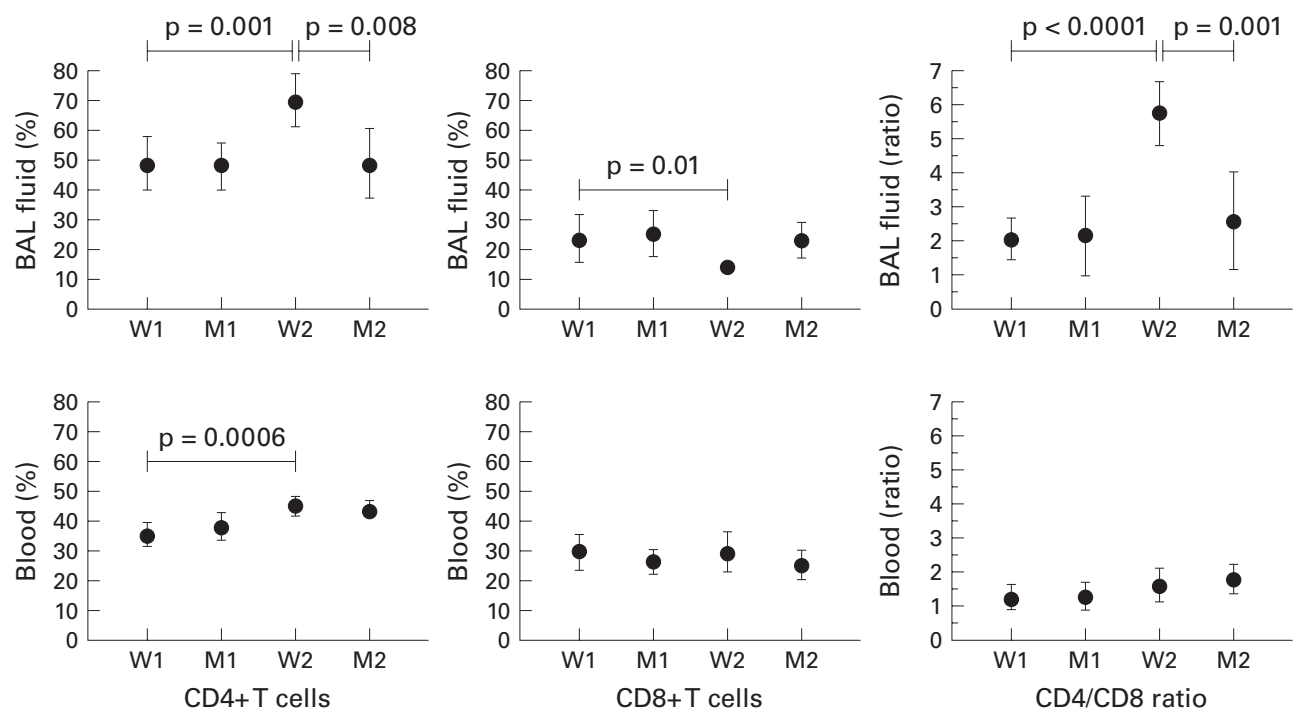

Figure 2 CD4+ and CD8+ T cells and CD4/CD8 ratio in BAL fluid and blood in women and men aged $\leqslant 40$ years $(W 1, M 1)$ and $>43$ years (W2, M2). Mean values are shown together with error bars at $95 \%$ confidence intervals. $p$ values $<0.01$ are considered significant.

Table 1 Cell numbers and subsets of lymphocytes in BAL fluid in women and men of different ages and correlation coefficients $(r)$ for the relationship between age and cell numbers in women and men

\begin{tabular}{|c|c|c|c|c|c|c|}
\hline & \multicolumn{2}{|l|}{$\leqslant 40$ years } & \multicolumn{2}{|l|}{$>43$ years } & \multicolumn{2}{|l|}{$r$} \\
\hline & Women & Men & Women & Men & All women & All men \\
\hline Total cells & $500(210-750)$ & $730(610-1020)$ & $540(80-720)$ & $490(360-860)$ & 0.06 & -0.28 \\
\hline Lymphocytes & $34(30-34)$ & $76(4-165)$ & $52(35-92)$ & $32(20-80)$ & 0.35 & -0.32 \\
\hline $\mathrm{CD} 3+(\mathrm{T})$ & $24(16-32)$ & $28(22-93)$ & $40(32-80)$ & $42(19-110)$ & 0.55 & -0.09 \\
\hline CD4+ (T helper) & $11(7-14)$ & $20(8-56)$ & $30(18-53)$ & $12(7-25)$ & 0.55 & -0.43 \\
\hline $\begin{array}{l}\text { CD8+ }(\mathrm{T} \\
\text { cytotoxic })\end{array}$ & $5(3-7)$ & $8(5-15)$ & $7(4-11)$ & $6(3-11)$ & 0.24 & -0.36 \\
\hline
\end{tabular}

Cell numbers $/ 1 \times 10^{4}$.

Values are medians (25th-75th percentiles).

seen between young and middle aged women (CD4+: mean 48\% (min-max $33-61 \%$ ) in young women and $69 \%(45-82 \%)$ in middle aged women, $\mathrm{p}=0.001$; CD8+: $23 \%(13-35 \%)$ in young women and $14 \%(9-19 \%)$ in middle aged women, $\mathrm{p}=0.01$, fig 2$)$.

In men neither $\mathrm{T}$ helper $(\mathrm{CD} 4+)$ cells, $\mathrm{T}$ cytotoxic $(\mathrm{CD} 8+)$ cells, nor the CD4/CD8 ratio correlated significantly with age $(r=0.1$, $\mathrm{p}=0.7 ; r=-0.26, \mathrm{p}=0.3$; and $r=0.17, \mathrm{p}=0.5$, respectively, fig 1 ). There were no significant differences between men $<40$ years of age and those aged $\geqslant 43$ years (figs 1 and 2 ). Large interindividual variations were present, especially between elderly men (fig 1 ).

Middle aged women ( $\geqslant 43$ years) and middle aged men ( $\geqslant 43$ years) differed significantly in the proportion of CD $4+$ cells $(\mathrm{p}=0.008)$ and the CD4/CD8 ratio ( $p=0.001$, fig 2). No sex related differences were present below 40 years of age.

Table 2 Correlation coefficients $(r$ ) for the relationship between the respective $T$ cell activation marker and age in women (W) and men (M)

\begin{tabular}{|c|c|c|c|c|c|c|}
\hline \multirow[b]{2}{*}{ Cells (\%) } & \multicolumn{3}{|l|}{ Blood } & \multicolumn{3}{|l|}{ BAL fluid } \\
\hline & Median & $r(W)$ & $r(M)$ & Median & $r(W)$ & $r(M)$ \\
\hline CD3+HLA-DR+ & $9(5-12)$ & 0.02 & 0.05 & $20(15-31)$ & 0.04 & -0.2 \\
\hline $\mathrm{CD} 3+\mathrm{CD} 25+$ & $15(12-19)$ & -0.4 & -0.3 & $7(6-8)$ & 0.2 & 0.2 \\
\hline CD3+CD69+ & $2(2-3)$ & 0.3 & 0.2 & $52(48-56)$ & -0.6 & 0.02 \\
\hline B cells & $10(9-13)$ & -0.37 & 0.2 & $1(1-2)$ & -0.1 & 0 \\
\hline NK cells & $13(10-16)$ & -0.3 & -0.2 & $4(3-6)$ & -0.3 & -0.1 \\
\hline
\end{tabular}

Values are medians $(25 \%-75 \%$ percentiles $)$.
The absolute number of $\mathrm{T}$ helper cells was not significantly correlated with age in women $(r=0.55, \mathrm{p}=0.15$ or men $(r=-0.43, \mathrm{p}=0.3): 11$ $(7-14) \times 10^{4}$ and $30(18-53) \times 10^{4}$ in women aged $<40$ and $>43$ years, respectively, and 20 $(8-56) \times 10^{4}$ and $12(7-25) \times 10^{4}$ in men aged $<40$ and $>43$ years, respectively (table 1 ).

BLOOD

In blood the percentage of CD4+ cells increased significantly with age in women $(r=0.65, \mathrm{p}=0.006)$ and men $(r=0.06, \mathrm{p}=0.011$, simple linear regression with Fisher's test), and younger and middle aged women differed significantly $(p=0.0006$, men $p=0.04$, mean comparison, fig 2). The percentage of CD8+ cells and the CD4/CD8 ratio did not change significantly with age either in women or in men (fig 2)

Activation markers (CD69, CD25, HLADR) on CD3 + cells did not differ significantly between men and women in blood or BAL fluid (table 2). No significant correlation was found between age and $\mathrm{T}$ cell activation markers in blood or BAL fluid in either sex.

\section{Discussion}

In this study we have shown that the composition of lymphocyte subsets in the lower airways changes with age in women but not in men. Furthermore, it was shown that the $\mathrm{T}$ cell changes in the BAL fluid of women appear in 
the fifth decade. The sex related differences found in BAL fluid were not found in peripheral blood. We found age related changes in the lymphocyte subsets in the BAL fluid of women (increasing levels of $\mathrm{T}(\mathrm{CD} 3+$ ) cells and $\mathrm{T}$ helper (CD4+) cells and increasing CD4/CD8 ratio with increasing age); no such age related changes were found in men. The most important finding was that the relationship between $\mathrm{T}$ helper and $\mathrm{T}$ cytotoxic cells changed markedly in women over 43 years of age. As a result of the significantly increased proportion of CD4+ cells and concomitant decrease in the proportion of CD8+ cells, the CD4/CD 8 ratio was much higher in women over 43 years of age than in women below 40 years. There was total discrimination in this respect, with the highest CD4/CD8 ratio in the younger women being lower than the lowest value in women over 43 years of age. Furthermore, the older group of women was quite homogeneous, whereas in men large interindividual differences were seen without any sign of altered CD4/CD8 ratio with age. No differences were seen in $\mathrm{T}$ helper and $\mathrm{T}$ cytotoxic cells in the lower airways between young women and men, but in the elderly population sex related differences were found because of the changed conditions in women. Thus, women over 43 years of age differed significantly from all other groups. However, if the cell numbers of men and women in the present investigation are pooled, our findings are in agreement with previous studies - that is, a slight increase with age in CD4+ cells and CD4/CD8 ratio in $\mathrm{BAL}$ fluid. ${ }^{19-22}$

It is possible that the age related changes seen in women are a consequence of diminishing fertility. In the early part of the fifth decade, the beginning of the menopause, the production of the female sexual hormones oestrogen and progesterone starts to diminish in the ovaries. ${ }^{23}$ The main action of female sexual hormones is to control reproduction (ovulation, fertilisation, implantation, and pregnancy) by partial suppression of the immune system in order to accept a fetus that is semiallogenic. ${ }^{24-29}$ In this context, cytotoxic $(\mathrm{CD} 8+) \mathrm{T}$ cells are believed to be the most important cells. The human endometrium contains a significant proportion of leucocytes (8-35\% of all cells), ${ }^{24}$ particularly NK and cytotoxic $\mathrm{T}$ cells, and the numbers vary reciprocally with hormone levels during the menstrual cycle and early in pregnancy. The reported changes in the lymphocyte compartment of the airways coincide with diminishing hormone production-that is, decreasing immunosuppressive effects. Progesterone and oestrogen are believed to act in opposite directions with regard to their effects on $\mathrm{T}$ cells. ${ }^{24-27}$

In agreement with other authors, we found that blood and BAL fluid have a different distribution of immune cells ${ }^{13} 15$ but we detected different age related changes in the blood and airways. Moreover, there were differences between the mucosal immune tissue system and the systemic lymphoid system. $^{30-32}$ Interestingly, the expression of CD25, CD69, and HLA-DR on BAL fluid T cells occurred in the same proportion as previously described on $T$ cells in the endometrium. ${ }^{24}$

More knowledge about the interaction between female hormones and mucous membranes in general would improve our understanding of diseases of the lungs and airways (interstitial lung diseases, non-allergic asthma, chronic dry cough) which are observed predominantly in women around the age of menopause.

In conclusion, the results of this study may have an impact in clinical practice. Because of the limited number of subjects in our study, the data need to be confirmed in other trials focusing on age and sex. The results would also have implications for reference values of BAL fluid cell constituents and corrections for age and sex may be necessary. Further characterisation of the putative interaction between female sexual hormones and the immune system is needed.

The authors thank Professor Kjell Carlström, Department of Obstetrics and Gynaecology, Huddinge University Hospital for his valuable help in understanding the complexity of hormonal changes in menopause. We also thank Anette Johnson and Charlotte Brundin for assistance with FACS analysis.

Funding: This study was supported by funds from The Swedish Heart Lung Foundation and by a grant from Glaxo Wellcome.

1 Wick G, Grubeck-Loebenstein B. Immunity and ageing. Dev Comp Immunol 1997;21:455-60.

2 Hodes RJ. Ageing and the immune system. Immunol Rev 1997; 160:5-8

3 Wick G, Grubeck-Loebenstein B. The ageing immune system: primary and secondary alterations of immune reactivity in the elderly. Exp Gerontol 1997;32:401-13.

4 Globerson A. T lymphocytes and ageing. Int Arch Allergy Appl Immunol 1995;107:491-7.

5 Mackall CL, Gress RE. Thymic ageing and T cell regeneration. Immunol Rev 1997;160:91-102.

6 Pawelec G, Adibzadeh M, Solana R, et al. The T cell in the ageing individual. Mech Ageing Dev 1997;93:35-45.

7 Murasko DM, Goonewardene IM. T cell function in aging: mechanisms of decline. Annu Rev Gerontol Geriatr 1990;10: 71-96.

8 Linton P-J, Hajnes L, Zhang X, et al. From naive to effector: Linton P-J, Hajnes L, Zhang X, et al. From naive to effect
alterations with ageing. Immunol Rev 1997;160:9-18.

9 Utsuyama M, Hirokawa K, Kurashima C, et al. Differential Utsuyama $M$, Hirokawa $K$, Kurashima C, et al. Differential
age-change in the numbers of CD4CD45RA+and age-change in the numbers of CD4CD45RA+and
CD4CD29+ $T$ cell subsets in human peripheral blood. CD4CD29+ T cell subsets in hum
Mech Ageing Dev 1992; 63:57-68.

10 Yamashiki M, Nishimura A, Kosaka Y, et al. Two-colour analysis of peripheral lymphocyte surface antigen in inherently healthy adults. F Clin Lab Anal 1994;8:22-6.

11 Stulning T, Maczek Ch, Böck G, et al. Reference intervals for human peripheral blood lymphocyte subpopulations from 'healthy' young and aged subjects. Int Arch Allergy Appl Immunol 1995;108:205-10.

12 Tollerud DJ, Clark JW, Brown LM, et al. The effects of cigarette smoking on T-cell subsets: a population-based survey rette smoking on T-cell subsets: a population-based survey 51 .

13 Costabel U, Bross $\mathrm{KJ}$, Reuter C, et al. Alteration in immunoregulatory T-cell subsets in cigarette smokers: a phenotypic analysis of bronchoalveolar lavage and blood phenotypic analysis of bronchoalveo
lymphocytes. Chest 1986;90:39-44.

14 Ratjen F, Bredendiek M, Zheng L, et al. Lymphocyte subsets in bronchoalveolar lavage fluid of children without bronchopulmonary disease. Am $\mathcal{f}$ Respir Crit Care Med 1995;152:174-8

15 Tamura N, Shirai T, Kira S. Flow cytometric analysis of lymphocyte subsets in the bronchoalveolar lavage fluid and peripheral blood of healthy volunteers. Scand 7 Immunol 1986;24:559-65.

16 Ancochea J, Gonzalea AMJ, Sanchez J, et al. Expression of lymphocyte surface antigens in bronchoalveolar lavage and peripheral blood cells from young healthy subjects. Chest 1993;104:32-7.

17 Thompson AB, Scholer SG, Daughton DM, et al. Altered epithelial lining fluid parameters in old normal individuals. f Gerontol 1992;47:M171-6.

18 Meyer KC, Ershler W, Rosenthal NS, et al. Immune dysregulation in the ageing human lung. Am $\mathcal{f}$ Respir Crit Care Med 1996;153:1072-9. 
19 Meyer KC, Soergel P. Variation of bronchoalveolar lymphocyte phenotypes with age in the physiologically normal 9;54:697-700.

20 The BAL Cooperative Group Steering Committee. Bronchoalveolar lavage constituents in healthy individuals, idiopathic pulmonary fibrosis and selected comparison groups. Am Rev Respir Dis 1990;141:169-202.

21 Lee BW, Yap HK, Chew FT, et al. Age- and sex-related changes in lymphocyte subpopulations of healthy Asian subjects: from birth to adulthood. Cytometry 1996;26:8-15.

22 Thoman ML, Weigle WO. The cellular and subcellular bases of immunosenescence. Adv Immunol 1989;46:22161.

23 Wise PM, Krajnak KM, Kashon ML. Menopause: the aging of multiple pacemakers. Science 1996;273:67-70.

24 Johnson PM, Cristmas SE, Vince GS. Immunological aspects of implantation and implantation failure. Human Reprod 1999;14(Suppl 2):26-36.

25 White HD, Yeaman GR, Givan AL, et al. Mucosal immunity in the human female reproductive tract: cytotoxic T lymphocyte function in the cervix and vagina of premenolymphocyte function in the cervix and vagina of premeno-
pausal and postmenopausal women. Am $\mathcal{F}$ Reprod Immunol pausal and postm
26 White HD, Crassi KM, Givan AL, et al. CD3+CD8+ CTL activity within the human female reproductive tract: influence of stage of the menstrual cycle and menopause. $f$ Immunol 1997;158:3017-27.

27 Booker SS, Jayanetti C, Karalak S, et al. The effect of progesterone on the accumulation of leukocytes in the human endometrium. Am f Obstet Gynecol 1994;171:139-42.

28 Grossman ChJ. Regulation of the immune system by sex steroids. Endocrinol Rev 1984;5:435-55.

29 Schuurs AH, Verheul HA. Effects of gender and sex steroids on the immune response. F Steroid Biochem 1990;35:157-72.

30 Pabst R, Tschering T. Lymphocytes in the lung: an often neglected cell. Numbers, characterisation and compartmentalization. Anat Embryol 1995;192:293-9.

31 Pabst R. Mucosa-associated lymphoid tissue: only one part of the dynamic lung lymphoid system. In: Holgate ST, Busse WW, eds. Asthma and rhinitis. Cambridge, MA: Blackwells, 1995:415-25.

32 Saltini C, Hemler ME, Crystal RG. T lymphocytes compartmentalized on the epithelial surface of the lower respiratory tract express the very late activation antigen complex
VLA-1. Clin Immunol Immunopathol 1988;46:221-33.

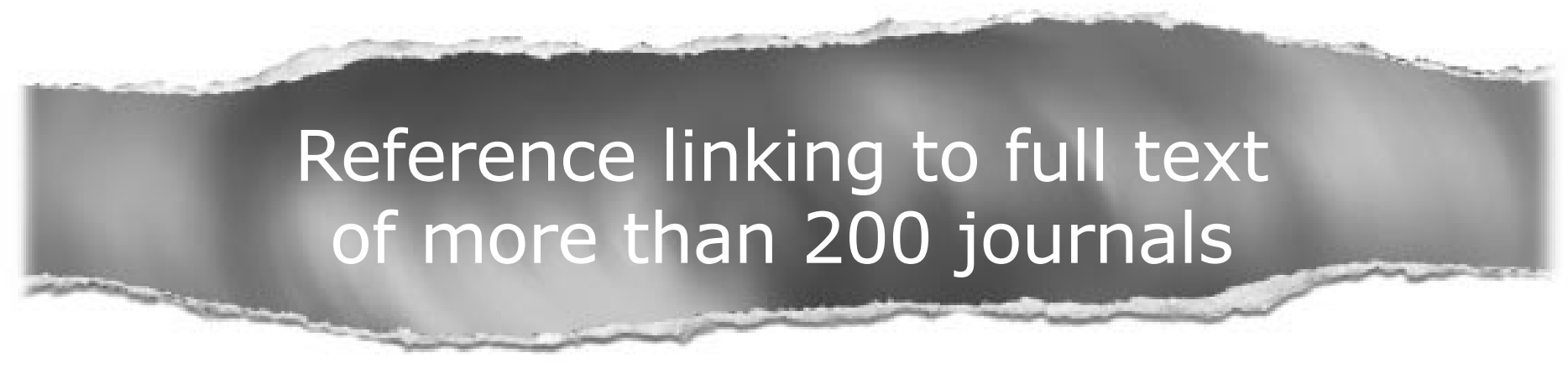

Toll free links

You can access the FULL TEXT of articles cited in Thorax online if the citation is to one of the more than 200 journals hosted by HighWire (http://highwire.stanford.edu) without a subscription to that journal. There are also direct links from references to the Medline abstract for other titles.

www.thoraxjnl.com 